\title{
Evaluation of anticancer agents using patient-derived tumor organoids characteristically similar to source tissues
}

\author{
HIROSUMI TAMURA $^{1}$, ARISA HIGA ${ }^{1}$, HIROTAKA HOSHI ${ }^{1}$, GEN HIYAMA ${ }^{1}$, NOBUHIKO TAKAHASHI ${ }^{1}$, \\ MASAE RYUFUKU ${ }^{1}$, GAKU MORISAWA ${ }^{1}$, YUKA YANAGISAWA ${ }^{1}$, EMI ITO ${ }^{1}$, JUN-ICHI IMAI ${ }^{1}$, \\ YUU DOBASHI ${ }^{1}$, KIYOAKI KATAHIRA ${ }^{1}$, SHU SOEDA $^{2}$, TAKAFUMI WATANABE ${ }^{2}$, \\ KEIYA FUJIMORI $^{2}$, SHINYA WATANABE ${ }^{1}$ and MOTOKI TAKAGI ${ }^{1}$ \\ ${ }^{1}$ Medical-Industrial Translational Research Center; ${ }^{2}$ Department of Obstetrics and Gynecology, \\ Fukushima Medical University, Fukushima, Fukushima 960-1295, Japan
}

Received February 21, 2018; Accepted June 4, 2018

DOI: 10.3892/or.2018.6501

\begin{abstract}
Patient-derived tumor xenograft models represent a promising preclinical cancer model that better replicates disease, compared with traditional cell culture; however, their use is low-throughput and costly. To overcome this limitation, patient-derived tumor organoids (PDOs) were established from human lung, ovarian and uterine tumor tissues, among others, to accurately and efficiently recapitulate the tissue architecture and function. PDOs were able to be cultured for $>6$ months, and formed cell clusters with similar morphologies to their source tumors. Comparative histological and comprehensive gene expression analyses proved that the characteristics of PDOs were similar to those of their source tumors, even following long-term expansion in culture. At present, 53 PDOs have been established by the Fukushima Translational Research Project, and were designated as Fukushima PDOs (F-PDOs). In addition, the in vivo tumorigenesis of certain F-PDOs was confirmed using a xenograft model. The present study represents a detailed analysis of three F-PDOs (termed REME9, 11 and 16) established from endometrial cancer tissues. These were used for cell growth inhibition experiments using anticancer agents. A suitable high-throughput assay system, with 96- or 384-well plates, was designed for each F-PDO, and the efficacy of the anticancer agents was subsequently evaluated. REME9 and 11 exhibited distinct responses and increased resistance to the drugs, as compared with conventional cancer cell lines (AN3 CA and RL95-2). REME9 and 11, which were established from tumors that originated in patients who did not respond to paclitaxel and carboplatin (the standard chemotherapy for endometrial cancer), exhibited high resistance
\end{abstract}

Correspondence to: Professor Motoki Takagi, Medical-Industrial Translational Research Center, Fukushima Medical University, 1 Hikariga-oka, Fukushima, Fukushima 960-1295, Japan

E-mail: m-takagi@fmu.ac.jp

Key words: patient-derived tumor organoid, patient-derived tumor xenograft, anticancer agents, molecular targeted drug, high-throughput assay, endometrial cancer (half-maximal inhibitory concentration $>10 \mu \mathrm{M}$ ) to the two agents. Therefore, assay systems using F-PDOs may be utilized to evaluate anticancer agents using conditions that better reflect clinical conditions, compared with conventional methods using cancer cell lines, and to discover markers that identify the pharmacological effects of anticancer agents.

\section{Introduction}

Historically, human cancer cell lines have been widely used for studies on cancer biology or as preclinical models to evaluate anticancer agents. However, these models may not reflect the characteristics of the source tumor tissues, as they are frequently passaged for long periods of time, which may alter their genome sequence, gene expression profile and morphology. In addition, almost all cell lines are cultured under monolayer conditions or used as xenografts in mice, which is not physically representative of tumor tissues $(1,2)$. Therefore, the clinical effects of anticancer agents are not identical to the results of evaluations performed with cancer cell lines. In fact, $\sim 85 \%$ of preclinical agents entering oncology clinical trials fail to demonstrate sufficient safety or efficacy to gain regulatory approval (3-5).

Currently, patient-derived tumor xenograft models (PDXs) are used as preclinical cancer models that better replicate the diversity of human cancer biology (6-11). Increasing evidence suggests that PDXs closely recapitulate human cancer biology and may be used to predict patient drug responses through direct comparisons between responses in patients and those in corresponding xenografts; however, the evaluation of anticancer agents using these models is difficult due to their lowthroughput nature and high associated cost (6-10). Therefore, since cost-effective techniques are required, in vitro systems, including patient-derived tumor organoid (PDO) or spheroid models that accurately recapitulate tissue architecture and function, have been developed recently. The establishment of human tumor organoids has been recently reported for colon (12-14), pancreatic (15), prostate (16), endometrial (17), and liver (18) tumors, among others. In particular, Pauli et al (19) reported 56 PDOs that were established from bladder, breast, brain, colon, lung, kidney, ovarian, pancreatic, prostate, stomach and uterine cancers, among others, in addition 
to the development of high-throughput screening (HTS) using these systems. In addition, Kondo et al (20) developed a cancer tissue-originated spheroid (CTOS) method based on the principle of retaining cell-cell contact throughout cancer cell preparation and culture; as such, CTOSs from various types of tumor tissues (e.g. colon, lung and endometrium) have been established, which have been used to evaluate anticancer agents (20-23). These PDOs are promising models to facilitate a better understanding of cancer biology and for the evaluation of drug efficacy in vitro, prior to employing PDXs. However, reports utilizing HTS and PDOs for the evaluation of anticancer agents have been limited.

In this study, a novel series of 53 PDOs was established from human tumor tissues, including those from the lung, breast, ovary, uterus, digestive organs and peritoneum, termed Fukushima (F)-PDOs, as presented in Table I. It was additionally confirmed that F-PDOs were able to be cultured for a long period of time and that they retained similar characteristics to those of source tumors based on histological and comprehensive gene expression analyses. In addition, the in vivo tumorigenesis of F-PDOs was tested using a xenograft model. Thus, to evaluate anticancer agents, a suitable HTS system using F-PDOs with multi-well plates was developed.

\section{Materials and methods}

Compounds. A total of 61 anticancer agents were used in the present study (Table II). Stock solutions $(10 \mathrm{mM})$ of the compounds were prepared in dimethyl sulfoxide (DMSO) and stored at $-80^{\circ} \mathrm{C}$ until use. The purity and integrity of all compounds were measured using ultra performance liquid chromatography-mass spectrometry (Waters Corporation, Milford, MA, USA) as follows (the injection volume was $1 \mu \mathrm{l}$ ): A Waters CORTECS C18 column (particle size, $1.6 \mu \mathrm{m}$; column size, $2.1 \times 50 \mathrm{~mm}$; Waters Corporation) was developed with aqueous acetonitrile $(\mathrm{MeCN})$ containing a $0.1 \%$ formic acid linear gradient system (5-90\% $\mathrm{MeCN}, 1.6 \mathrm{~min}$; flow rate, $1 \mathrm{ml} \mathrm{min}{ }^{-1}$ ) at $40^{\circ} \mathrm{C}$, verifying the ultraviolet (UV) adsorption and mass of the major UV peaks (Table II).

Establishment of F-PDOs. The present study was approved by the Institutional Animal Care and Use Committee of Fukushima Medical University (Fukushima, Japan). Solid tumor tissues obtained from surgical or biopsy specimens, and ascites and pleural fluids, were acquired from patients with cancer at Fukushima Medical University Hospital, upon providing informed consent. Ascites and pleural fluids were centrifuged at $400 \mathrm{xg}$ for $3 \mathrm{~min}$ at room temperature to concentrate the tumor tissues, and the supernatants were removed. Parts of the solid tumor tissues, and their associated tissues from ascites and pleural fluids, were used for comprehensive gene expression analysis and histological analysis. Solid tumor tissues were also cut up into small $\left(\sim 1 \mathrm{~mm}^{3}\right)$ pieces with a scalpel. The minced and concentrated tumor tissues were cultured as suspension cultures for 3-6 months to establish the F-PDOs. For example, REME16 cells were derived from the ascites of a patient with adenocarcinoma of the endometrium. Ascites collected from the patient was centrifuged at $400 \mathrm{x}$ g for $3 \mathrm{~min}$ at room temperature and the tumor tissues were concentrated. The tumor tissues were cultured in
Table I. Established F-PDOs.

Tissue Number of F-PDOs

$\begin{array}{lr}\text { Lung } & 15 \\ \text { Breast } & 2 \\ \text { Ovary } & 12 \\ \text { Uterus } & 18 \\ \text { Digestive organs } & 3 \\ \text { Peritoneal } & 3 \\ \text { Total } & 53\end{array}$

F-PDO, Fukushima patient-derived organoid.

$5 \mathrm{ml}$ modified FBIM002 medium (Fukushima Translational Research Project, Fukushima, Japan) supplemented with $1 \%$ penicillin-streptomycin mixed solution (cat. no. 26253-84; Nacalai Tesque, Inc., Kyoto, Japan) using ultra-low attachment 6-well plates (cat. no. 3471; Corning Incorporated, Corning, $\mathrm{NY}$, USA) at $37^{\circ} \mathrm{C}$ in a humidified incubator with $5 \% \mathrm{CO}_{2}$. The $50-80 \%$ of the volume of the medium was changed twice weekly, while observing the condition of the cells. Subculture was performed when the concentration of the cells was not increased and cellular debris or single cells were increased in the culture medium. The organoids were cultured under the same conditions for the following 60 days. During this time, they were observed under a microscope (Leica DMC2900; Leica Microsystems GmbH, Wetzlar, Germany), to identify alterations in cellular morphology. When REME16 cells had been established as an F-PDO, the organoids were stored in liquid nitrogen vapor phase. The cryopreserved REME16 cells were thawed and cultured in FBIM002 medium, and it was confirmed that they were capable of culture for $>3$ months.

F-PDOs were tested for pathogens [human immunodeficiency virus (HIV), hepatitis C virus (HCV), hepatitis B virus (HBV) and Treponema pallidum] with the StepOnePlus Real-Time Polymerase Chain Reaction System (Thermo Fisher Scientific, Inc., Waltham, MA, USA) using HIV Real-TM Qual (cat. no. R-V0-100FRT; Sacace Biotechnologies Srl, Como, Italy), HCV Real-TM Qual (cat. no. V1-100FRT; Sacace Biotechnologies Srl), HBV Real-TM Qual (cat. no. V5-100FRT; Sacace Biotechnologies Srl), and Treponema pallidum Real-TM (cat. no. B20-100FRT; Sacace Biotechnologies Srl), respectively, according to the manufacturer's protocols. All F-PDOs were negative.

Cell culture. F-PDOs were cultured in $15 \mathrm{ml}$ FBIM002 using ultra-low attachment $75-\mathrm{cm}^{2}$ flasks (cat. no. 3814; Corning Incorporated) at $37^{\circ} \mathrm{C}$ in a humidified incubator with $5 \% \mathrm{CO}_{2}$. Since accurate cell numbers of F-PDOs were not able to be determined using a cell counter, the cell pellet volume following centrifugation of the cell suspension was visually measured by comparing the F-PDO pellet in a $15-\mathrm{ml}$ tube with tubes marked at 50, 75, 100 and $150 \mu \mathrm{l}$ volume. The 50-80\% medium was changed twice weekly. When F-PDOs reached their maximum saturation density, the cells were passaged at a 1:2 ratio. In detail, F-PDO suspensions were transferred from the flask to a $15-\mathrm{ml}$ tube and centrifuged at $200 \mathrm{x}$ g for $2 \mathrm{~min}$ at 
Table II. Anticancer agents used in the present study.

\begin{tabular}{|c|c|c|c|}
\hline Compound & Target & Supplier & Purity, \% \\
\hline Nilotinib & ABL & Carbosynth & 100 \\
\hline Ponatinib & ABL, Kit, Ret, FGFR & LC Laboratories & 100 \\
\hline DCC-2036 & ABL, SRC, FLT3 & AdooQ BioScience & 100 \\
\hline GDC-0068 & $\mathrm{AKT}$ & MedChemExpress & 100 \\
\hline Ceritinib & ALK & Chemietek & 100 \\
\hline Crizotinib & ALK, HGFR & LC Laboratories & 100 \\
\hline Entrectinib & ALK, TrkA, B, and C, ROS1 & MedChemExpress & 100 \\
\hline Bicalutamide & Androgen & Enzo Life Sciences & 100 \\
\hline Pentostatin & Antimetabolite & Toront Research Chemicals & 100 \\
\hline Elesclomol & Apoptosis & Selleck Chemicals & 100 \\
\hline Aminoglutethimide & Aromatase & MP Biomedicals & 100 \\
\hline Obatoclax & $\mathrm{Bcl}$ & LC Laboratories & 100 \\
\hline Ibrutinib & Btk & MedChemExpress & 100 \\
\hline Tacrolimus & Calcineurin & LC Laboratories & 100 \\
\hline PAC-1 & Caspase & AdooQ BioScience & 100 \\
\hline Dinaciclib & CDK & Cayman Chemical & 100 \\
\hline PHA-793887 & CDK & AdooQ BioScience & 100 \\
\hline Dexamethasone & Corticosteroid & Fujifilm Wako & 100 \\
\hline Methotrexate & Dihydrofolate reductase & Fujifilm Wako & 100 \\
\hline Leflunomide & Dihydroorotate dehydrogenase & TCI & 100 \\
\hline Etoposide & DNA topoisomerase & Fujifilm Wako & 100 \\
\hline Melphalan & DNA alkylation & Fujifilm Wako & 100 \\
\hline Temozolomide & DNA alkylation & Fujifilm Wako & 100 \\
\hline Decitabine & DNA demethylating & TCI & 100 \\
\hline Fluorouracil & DNA synthesis & Fujifilm Wako & 100 \\
\hline Mitomycin C & DNA synthesis & Fujifilm Wako & 100 \\
\hline Carboplatin & DNA synthesis & TCI & 100 \\
\hline Mycophenolic acid & DNA synthesis & TCI & 100 \\
\hline Erlotinib & EGFR & Carbosynth & 100 \\
\hline Afatinib & EGFR, HER2 & Selleck Chemicals & 100 \\
\hline Lapatinib & EGFR, HER2 & LC Laboratories & 100 \\
\hline Tamoxifen & Estrogen & Fujifilm Wako & 100 \\
\hline GSK126 & $\mathrm{EZH} 2$ & AdooQ BioScience & 100 \\
\hline AZD 4547 & FGFR & Active Biochem & 100 \\
\hline Entinostat & HDAC & Carbosynth & 100 \\
\hline Panobinostat & HDAC & Cayman Chemical & 98.19 \\
\hline Belinostat & HDAC & Selleck Chemicals & 100 \\
\hline PCI-34051 & HDAC & Selleck Chemicals & 98.28 \\
\hline Tubastatin A & HDAC & Selleck Chemicals & 100 \\
\hline Vismodegib & Hedgehog & LC Laboratories & 100 \\
\hline Varlitinib & HER2, EGFR & Selleck Chemicals & 97.51 \\
\hline Tivantinib & HGFR & MedChemExpress & 100 \\
\hline Foretinib & HGFR, VEGFR, PDGFR, Kit, FLT3, Tie, Ron & Selleck Chemicals & 99.01 \\
\hline Ganetespib & HSP90 & Selleck Chemicals & 100 \\
\hline Alvespimycin & HSP90 & Selleck Chemicals & 100 \\
\hline AGI-6780 & IDH2(R140Q) & MedChemExpress & 97.68 \\
\hline BMS-754807 & IGF & Chemscene & 98.52 \\
\hline OSI-906 & IGF & Chemietek & 100 \\
\hline Ruxolitinib & JAK & Chemscene & 100 \\
\hline AZD 6244 & MEK & LC Laboratories & 100 \\
\hline Binimetinib & MEK & Active Biochem & 100 \\
\hline Rapamycin & mTOR & LC Laboratories & 100 \\
\hline
\end{tabular}


Table II. Continued.

\begin{tabular}{|c|c|c|c|}
\hline Compound & Target & Supplier & Purity, \% \\
\hline Everolimus & mTOR & AdooQ BioScience & 97.97 \\
\hline MLN-4924 & NAE & AdooQ BioScience & 100 \\
\hline Olaparib & PARP & AdooQ BioScience & 100 \\
\hline Tandutinib & PDGFR, Kit, FLT3 & LC Laboratories & 100 \\
\hline Idelalisib & PI3K & AdooQ BioScience & 100 \\
\hline NVP-BKM120 & PI3K & AdooQ BioScience & 100 \\
\hline GDC-0980 & PI3K, mTOR & MedChemExpress & 98.63 \\
\hline Volasertib & PLK & Chemietek & 100 \\
\hline Carfilzomib & Proteasome & Chemietek & 100 \\
\hline Bortezomib & Proteasome & AdooQ BioScience & 100 \\
\hline Dabrafenib & BRAF & AdooQ BioScience & 100 \\
\hline Vemurafenib & BRAF & ChemScene & 100 \\
\hline RO-4929097 & Secretase & AdooQ BioScience & 100 \\
\hline AZD 0530 & $\mathrm{SRC}, \mathrm{ABL}$ & ChemScene & 100 \\
\hline BX-795 & TBK, PDK, IKK & AdooQ BioScience & 97.34 \\
\hline Lenalidomide & Thalidomide & AdooQ BioScience & 100 \\
\hline Paclitaxel & Tubulin & TCI & 100 \\
\hline Vindesine & Tubulin & Sigma-Aldrich & 100 \\
\hline Nutlin-3 & Ubiquitin & KareBay Biochem & 100 \\
\hline Brivanib & VEGFR, FGFR & AdooQ BioScience & 100 \\
\hline Sunitinib & VEGFR, FGFR, PDGFR, Kit, FLT3 & Cayman Chemical & 96.85 \\
\hline Regorafenib & VEGFR, Kit, Ret, FGFR, PDGFR & MedChemExpress & 100 \\
\hline
\end{tabular}

Active Biochemicals Co., Ltd. (Kowloon, Hong Kong); AdooQ BioScience (Irvine, CA, USA); Carbosynth, Ltd. (Compton, UK); Cayman Chemical Company (Ann Arbor, MI, USA); Chemietek (Indianapolis, IN, USA); ChemScene (Monmouth Junction, NJ, USA); Enzo Life Sciences, Inc. (Farmingdale, NY, USA); Fujifilm Wako Pure Chemical, Ltd. (Osaka, Japan); KareBay Biochem, Inc. (Monmouth Junction, NJ, USA); LC Laboratories (Woburn, MA, USA); MedChemExpress (Monmouth Junction, NJ, USA); MP Biomedicals, LLC (Santa Ana, CA, USA); Selleck Chemicals (Houston, TX, USA); Sigma-Aldrich (Merck KGaA, Darmstadt, Germany); TCI Co., Ltd. (Tokyo, Japan); Toronto Research Chemicals (North York, ON, Canada).

room temperature. Following removal of the supernatant, $10 \mathrm{ml}$ medium was added to the pelleted cells and gently mixed five times. A total of one-half of the cell suspension was subsequently seeded into a flask containing $10 \mathrm{ml}$ fresh medium.

Cancer cell lines (AN3 CA, KLE, RL95-2 and SK-UT-1B) were purchased from the American Type Culture Collection (Manassas, VA, USA). The cells were cultured at $37^{\circ} \mathrm{C}$ in a humidified incubator with $5 \% \mathrm{CO}_{2}$. All cell culture media were supplemented with fetal bovine serum (cat. no. 172012; Sigma-Aldrich; Merck KGaA, Darmstadt, Germany) and penicillin-streptomycin solution (cat. no. 168-23191; Fujifilm Wako Pure Chemical, Ltd., Osaka, Japan) at final concentrations of 10 and 1\%, respectively. AN3 CA and SK-UT-1B cells were maintained in Eagle's minimum essential medium (cat. no. 051-07615; Fujifilm Wako Pure Chemical, Ltd.). KLE cells were cultured in Dulbecco's modified Eagle's medium (DMEM)/F-12, 4-(2-hydroxyethyl)-1-piperazineethanesulphonic acid (HEPES) medium (cat. no. 11330; Thermo Fisher Scientific, Inc.). RL95-2 cells were grown in DMEM/F-12, HEPES medium supplemented with $5 \mu \mathrm{g} / \mathrm{ml}$ insulin (cat. no. 097-06474; Fujifilm Wako Pure Chemical, Ltd.). Cell number and viability were automatically measured using trypan blue dye exclusion with a Vi-Cell XR Cell Viability
Analyzer (Beckman Coulter, Inc., Brea, CA, USA), according to the manufacturer's protocol.

Histological analysis. F-PDOs were fixed using 4\% paraformaldehyde for $1 \mathrm{~h}$ at room temperature, and washed with PBS. Subsequently, F-PDOs were embedded using iPGell (cat. no. GSPG20-1; GenoStaff Co., Ltd., Tokyo, Japan). The blocks were embedded in paraffin and sections $(3-\mu \mathrm{m})$ were obtained for histological analysis. Hematoxylin and eosin (HE) staining was performed using a DRS-Prisma-J0D (Sakura Finetek Japan, Tokyo, Japan) automated slide stainer. Xenograft tumor tissues were fixed using $10 \%$ neutral buffered formalin solution at least $24 \mathrm{~h}$ at room temperature, and the following steps, including paraffin embedding, paraffin sectioning and $\mathrm{HE}$ staining, were performed under contract with BoZo Research Center, Inc. (Tokyo, Japan). Paraffin-embedded tissues were sliced to 3- $\mu \mathrm{m}$. HE-stained samples were observed using an upright light microscope (magnification, x40; BX43; Olympus, Corporation, Tokyo, Japan).

Comprehensive gene expression analysis. Comprehensive gene expression analysis was performed according to previous reports (24-26). Briefly, synthetic polynucleotides (80-mers) 
representing 14,400 human transcripts (MicroDiagnostic, Inc., Tokyo, Japan) were arrayed using a custom arrayer. Total RNA was extracted from the cells using ISOGEN (Nippon Gene Co., Ltd., Tokyo, Japan) and $5 \mu \mathrm{g}$ was labeled using SuperScript II (Invitrogen; Thermo Fisher Scientific, Inc.) and cyanine 5-dUTP (PerkinElmer, Inc., Waltham, MA, USA) for samples, or cyanine 3-dUTP (PerkinElmer, Inc.) for human common reference RNA, which was prepared by mixing equal amounts of total RNA extracted from 22 cell lines. Hybridization was performed with a labeling and hybridization kit (MicroDiagnostic, Inc.). Signals were measured with a GenePix 4000B scanner (Molecular Devices, LLC, Sunnyvale, CA, USA).

The signals were converted into primary expression ratios (ratio of cyanine-5 intensity of each sample to cyanine- 3 intensity of the human common reference RNA). Each ratio was normalized through multiplication using normalization factors and Gene Pix Pro 3.0 software (Molecular Devices, LLC). The primary expression ratios were converted to $\log _{2}$ values (designated as log ratios). Spots that exhibited fluorescence intensities below the detection limit were assigned a log ratio value of 0 and were not included in the signal calculations of the averages and subtracted $\log$ ratios. The data were processed using Microsoft Office Excel 2016, version 16.0.4266.1001 (Microsoft Corporation, Redmond, WA, USA) and the ExpressionView_Pro Version 3.3.8.1 (MicroDiagnostic, Inc.). Cluster analysis was performed using the unweighted pair group method with arithmetic mean hierarchical clustering method (24).

Assessment of tumorigenesis using a xenograft model. These experiments were performed with the approval of the Institutional Animal Care and Use Committee of Fukushima Medical University. Tumorigenesis of F-PDOs was examined using immunodeficient NOG (NOD.Cg-Prkd $c^{\text {scid }} l l 2 r g^{\mathrm{tm} 1 \mathrm{Sug} /}$ ShiJic) mice (27). A total of three male NOG mice (6-8 weeks old; 20-22 g) were obtained from the Central Institute for Experimental Animals (Kawasaki, Japan). All mice were housed in plastic cages (136x208x115 mm) within a safety rack (CLEA Japan, Inc., Tokyo, Japan) in a pathogen-free state, at a temperature of $22 \pm 2{ }^{\circ} \mathrm{C}$ with $55 \pm 5 \%$ humidity, and a 12-h light/12-h dark cycle. The plastic cages, bedding and filter caps for these mice were sterilized either in an autoclave or via gas sterilization. The mice were allowed ad libitum access to commercial diet sterilized by gamma irradiation at 30 kGy (CE-2; CLEA Japan, Inc.) and ultra-filtered membrane water. REME9, REME11 and REME16 (34-70 mg) lines were suspended in $0.1 \mathrm{ml}$ Hanks' balanced salt solution without magnesium and calcium (cat. no. 085-09355; Fujifilm Wako Pure Chemical, Ltd.), and were injected subcutaneously into the back of the NOG mice using a $1-\mathrm{ml}$ syringe with a $26 \mathrm{G}$ needle (28). Tumor sizes were estimated by performing twodimensional caliper measurements once per week; the formula for estimating the volume of the ellipsoid tumor was $\mathrm{Lx} \mathrm{W}^{2} / 2$, where $\mathrm{L}$ is the length of the major axis and $\mathrm{W}$ is the width of the tumor (29).

Growth inhibition assays using multi-well plates. The growth inhibitory activity of anticancer agents against F-PDOs was assayed by measuring the amount of 5 ' adenosine triphosphate (ATP) in the cells using the CellTiter-Glo 3D Cell Viability
Assay (Promega Corporation, Madison, WI, USA). F-PDOs were cultured in flasks until sufficient numbers of cells were present for the assay. A total of 1 day prior to seeding, the F-PDOs were transferred from a $75-\mathrm{cm}^{2}$ flask to a $15-\mathrm{ml}$ tube and centrifuged at $200 \mathrm{x}$ g for $2 \mathrm{~min}$ at room temperature to measure the cell pellet volume. Subsequently, the cell pellet was suspended with $15 \mathrm{ml}$ fresh medium. The suspension was transferred to a $75-\mathrm{cm}^{2}$ flask and cultured in an incubator. After $24 \mathrm{~h}$, the F-PDO was minced using a CellPet FT (JTEC Corporation, Osaka, Japan) set with a filter holder containing a $70-\mu \mathrm{m}$ mesh filter. The F-PDO suspension was diluted 10- or 20-fold and seeded into 96-well roundbottomed, ultra-low attachment microplates (cat. no. 7007; Corning Incorporated) with $150 \mu \mathrm{l}$ medium using a Multidrop Combi dispenser (Thermo Fisher Scientific, Inc.). To monitor apoptosis activity, CellEvent ${ }^{\mathrm{TM}}$ Caspase-3/7 Green Detection Reagent (cat. no. C10423; Thermo Fisher Scientific, Inc.) was added to each well. F-PODs were incubated for $24 \mathrm{~h}$ and then treated with $0.1-\mu$ l solutions containing the agent at final concentrations ranging between $10 \mu \mathrm{M}$ and $1.5 \mathrm{nM}$ (nine serial dilutions) using an ADS-348-8 Multistage-dispense station (Biotec Co., Ltd., Tokyo, Japan). DMSO was used as the vehicle control at a maximum concentration of $0.1 \%$. The dynamics of apoptosis activity were monitored using an IncuCyte ZOOM live cell imaging system (Essen BioScience, Ann Arbor, MI, USA) and IncuCyte ZOOM version 2016B (Essen BioScience). The plates were placed in an IncuCyte for 6 days to monitor caspase-3/7 activation through the capture of green-filter images ( $\lambda \mathrm{ex}, 440-480 \mathrm{~nm}$; $\lambda \mathrm{em}, 504-544 \mathrm{~nm}$ ) of the cells every $6 \mathrm{~h}$. After $144 \mathrm{~h}, 40 \mu \mathrm{l}$ CellTiter-Glo 3D reagent solution (Promega Corporation) was added to each well. The plates were mixed using a mixer and incubated for $10 \mathrm{~min}$ at $30^{\circ} \mathrm{C}$. Luminescence was measured using an EnSpire plate reader (PerkinElmer, Inc.). Cell viability was calculated by dividing the amount of ATP in the test wells by that in the vehicle control wells, with the background subtracted. The growth rate over 6 days was calculated by dividing the amount of ATP in the wells without anticancer agents by that in the vehicle control wells $24 \mathrm{~h}$ after seeding.

HTS using 384-well plates was conducted as performed for the 96-well plates, except for the volume used for seeding and the agent concentration range. A total of $40 \mu \mathrm{l} \mathrm{F-PDO}$ suspension was seeded in 384-well round-bottomed, ultra-low attachment spheroid microplates (cat. no. 4516; Corning Incorporated) using with a dispenser. At $24 \mathrm{~h}$ after seeding, F-PDOs were treated with $0.04-\mu 1$ solutions of agent at final concentrations ranging between $20 \mu \mathrm{M}$ and $1.0 \mathrm{nM}$ (ten serial dilutions) using an Echo 555 (Labcyte, Inc., San Jose, CA, USA). After $144 \mathrm{~h}, 10 \mu \mathrm{l}$ CellTiter-Glo 3D reagent solution was added to the medium and the luminescence was measured.

The half-maximal inhibitory concentration $\left(\mathrm{IC}_{50}\right)$ and area under the curve (AUC) values were calculated from the doseresponse curves and analyzed using Morphit version 5.0 (The Edge Software Consultancy, Ltd., Guildford, UK). The data represent the mean \pm standard deviation of triplicate experiments. The $Z^{\prime}$ factor, a dimensionless parameter that ranges between 1 (infinite separation) and $<0$, was defined as $Z^{\prime}=1$ - $(3 \sigma \mathrm{c}++3 \sigma \mathrm{c}-) / \mathrm{l} \mu \mathrm{c}+-\mu \mathrm{c}-\mathrm{l}$, where $\sigma \mathrm{c}+, \sigma \mathrm{c}-, \mu \mathrm{c}+$ and $\mu \mathrm{c}-$ are the standard deviations $(\sigma)$ and averages $(\mu)$ of the high $(\mathrm{c}+)$ and low (c-) controls (30). 

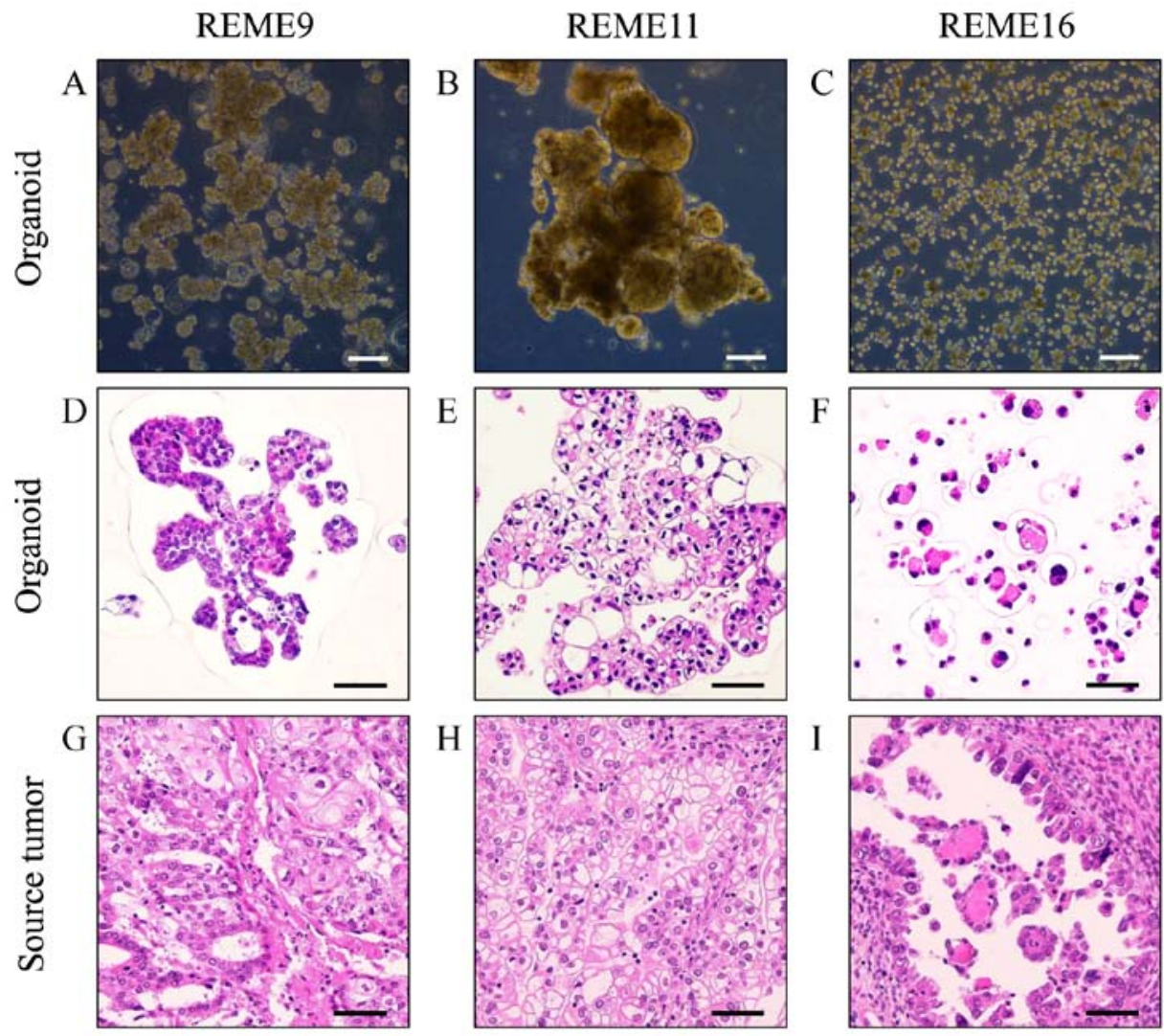

Figure 1. Phase-contrast and HE-stained images of the Fukushima patient-derived organoids and their source tumors. Phase-contrast images of (A) REME9, (B) REME11 and (C) REME16 were obtained using a x10 objective. HE-stained images of the organoids (D) REME9, (E) REME11 and (F) REME16, and the source tumors of (G) REME9, (H) REME11 and (I) REME16, were viewed using a x40 objective. The source tumor of the REME16 line was not ascites; it was a peritoneal metastasis from an endometrial tumor. Scale bars: Phase-contrast images, $200 \mu \mathrm{m}$; HE-stained images, $50 \mu \mathrm{m}$. HE, hematoxylin and eosin.

F-PDOs from endometrial cancer tissues

Endometrial cancer tissues (source tissues for F-PDOs)

$\square$ Endometrial cancer tissues

$\square$ Endometrial cancer cell lines

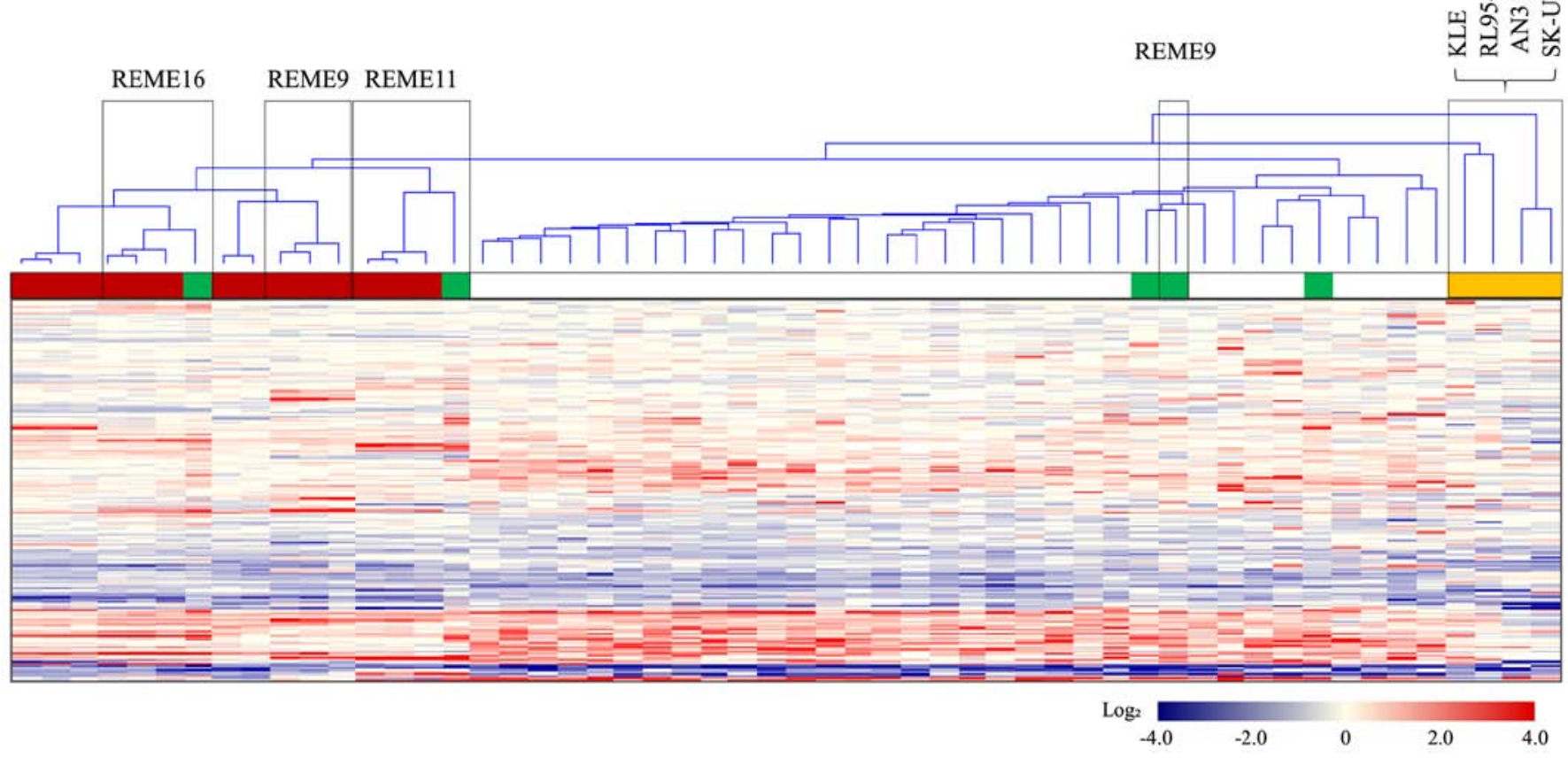

Figure 2. Gene expression profiles of F-PDOs, endometrial tumors and endometrial cancer cell lines. Expression values (subtracted log ratios) are represented by color gradients. Red and blue colors indicate high and low expression, respectively. White indicates a log ratio of 0 . F-PDO, Fukushima patient-derived organoid. 


\section{Results}

Establishment of F-PDOs. The present study attempted to establish organoids from lung, breast, ovarian, uterine and digestive organ tumor tissues using an independently developed method, which had the following characteristics: (i) Tumor tissues were cut without tissue-dissolving enzymes, for example trypsin or collagenase; (ii) F-PDOs were cultured in suspension without extracellular matrix; and (iii) F-PDOs expand for long periods of time in culture, based on the principle of retaining the histological architecture of their source tissue. Thus, during long periods of culture, almost all stromal cells were removed except for cancer cells, and heterogeneous tumor organoids were cultured. F-PDOs formed cell clusters that exhibited various heterogeneous morphologies. Furthermore, F-PDOs were able to be cultured for $>6$ months and cryopreserved for future use. At present, 53 F-PDOs have been established from several tumor tissues (Table I). The present study describes the characteristics of three F-PDOs (REME9, 11 and 16) established from endometrial cancer tissues, in addition to HTS using these F-PDOs.

Characterization of F-PDOs. To investigate whether the REME9, 11 and 16 lines had similar characteristics to their source tumor tissues, histological and comprehensive gene expression analyses were performed. REME9 was from endometrial cancer tissue, which was pathologically diagnosed as endometrioid adenocarcinoma with squamous differentiation. REME11 and 16 were from clear cell adenocarcinoma specimens. REME9 was a mixture of cells with different morphological features (Fig. 1A). The majority of REME9 cells appeared as big cell clusters that were $\sim 100-500 \mu \mathrm{m}$ in diameter. Certain organoids were $\sim 100 \mu \mathrm{m}$ and included hollow cells. Cell debris existed in the culture. REME11 grew as large cell clusters of $300-1,000 \mu \mathrm{m}$, which were composed of round and elliptical cells of $100-200 \mu \mathrm{m}$ (Fig. 1B). These cell clusters frequently merged to form clusters that were $>1,000 \mu \mathrm{m}$ in diameter. REME16 comprised primarily round cells that were $<50 \mu \mathrm{m}$ (Fig. 1C). Although the cells sometimes formed clusters, they were rarely $>100 \mu \mathrm{m}$, unlike REME9 and 11 . The doubling times of REME9, 11 and 16 were $~ 5,8$ and 6 days, respectively.

Subsequently, REME9, 11 and 16, and their source tissues, were stained with HE for histological evaluation. HE-stained images of REME9, 11, and 16 (Fig. 1D-F) were similar to those of their source tissues (Fig. 1G-I). REME9 was characterized by its resemblance to endometrioid adenocarcinoma in accordance with the source tissue (Fig. 1D and G). REME11 and its source tissue clearly possessed characteristics of clear cell adenocarcinoma, specifically the presence of clear cytoplasm (Fig. 1E and H). Images of REME16 and its source tissue illustrated a glandular structure with eosin-positive material at the center of the spheroid (Fig. 1F and I).

Gene expression profiles were obtained from five F-PDOs from endometrial tumor tissues, source endometrial tumor tissues, various other endometrial tumor tissues (31 samples), and five cell lines (AN3 CA, KLE, RL95-2 and SK-UT-1B) derived from endometrial cancer. Furthermore, samples used for this analysis included different generations of the same F-PDO, in addition to two different types of endometrial tumor-derived F-PDOs in addition to REME9, 11 and 16. Cluster analysis of gene expression profiles was performed
Table III. High-throughput screening performance using Fukushima patient-derived organoids and 96- or 384-well microplates.

\begin{tabular}{llccc}
\hline Plate size & \multicolumn{1}{c}{ Factor } & REME9 & REME11 & REME16 \\
\hline 96-well & CV, \% & 1.12 & 3.08 & 0.74 \\
& Z'-factor & 0.97 & 0.91 & 0.98 \\
& Growth rate & 2.97 & 2.31 & 2.77 \\
384-well & CV, \% & 5.38 & 21.65 & 4.44 \\
& Z'-factor & 0.84 & 0.35 & 0.87 \\
& Growth rate & 5.16 & 3.56 & 4.01 \\
\hline
\end{tabular}

$\mathrm{CV}$, coefficient of variation.

with the resultant 2,579 genes, which indicated variation in gene expression among all samples, as presented in Fig. 2. This analysis resulted in the presence of two groups: The first group consisted of F-PDOs and endometrial tumors, and the second group comprised cancer cell lines. The profiles of F-PDOs were completely different from those of the cell lines, although similar to those of the endometrial tumors. The differences between the profiles of F-PDOs and those of endometrial tumors may be due to the fact that stromal cells were removed from their source tissues during F-PDO culture. These results indicated that F-PDOs possessed characteristics of the source tissues, although they were not similar to endometrial cell lines.

To verify in vivo tumorigenesis, REME9, 11 and 16 F-PDOs were xenografted subcutaneously into NOG mice. All F-PDOs were confirmed to engraft in NOG mice 6 days post-inoculation, and thus demonstrated in vivo tumorigenesis (representative data presented in Fig. 3A). However, growth rates among the three F-PDOs were different. The growth rate of REME9 was highest, as the tumor size was $481.6 \mathrm{~mm}^{3} 24$ days postgrafting. The growth rate of REME11 was very slow, requiring 120 days to reach a tumor size of $400 \mathrm{~mm}^{3}$. The tumor size of REME16 increased to $200 \mathrm{~mm}^{3}$ within 70 days. The tissues from REME9, 11 and 16 xenografts were stained with HE, and histologically observed. Resulting images showed tissue characteristics that were identical to those of their source F-PDOs and tissues (Figs. 1 and 3B). Furthermore, the gene expression profiles of REME9, 11 and 16 xenografts were similar to those of their source F-PDOs and tissues (data not shown).

Development of a cell growth inhibition assay using F-PDOs. To evaluate anticancer agents using F-PDOs, the present study aimed to develop an HTS assay using 96- or 384-well microplates. In preliminary experiments, it was difficult to obtain high precision data with multi-well plates, as the majority of F-PDOs form large cell clusters that cannot be dispensed equally into each well. Therefore, CellPet FT with a 70- $\mu \mathrm{m}$ mesh filter was used to mince the F-PDOs, which were subsequently seeded into microplates as presented in Fig. 4. F-PDOs were incubated for 7 days following seeding. To count viable cells, the ATP content was measured. HTS performance was evaluated by computing the coefficients of variation $(\mathrm{CV})$ and the $Z^{\prime}$-factor. The $Z^{\prime}$-factor has been widely accepted for the evaluation of assay quality and performance (30), and an assay 


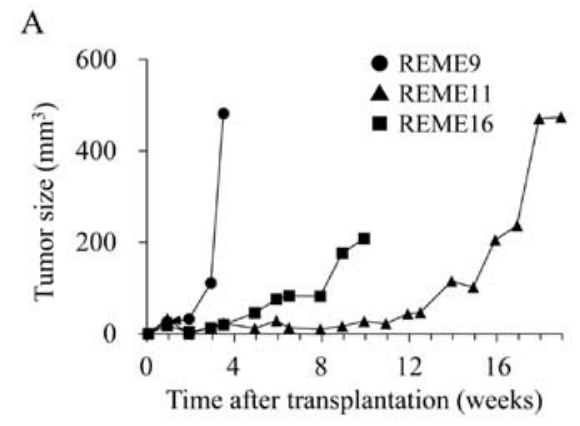

B
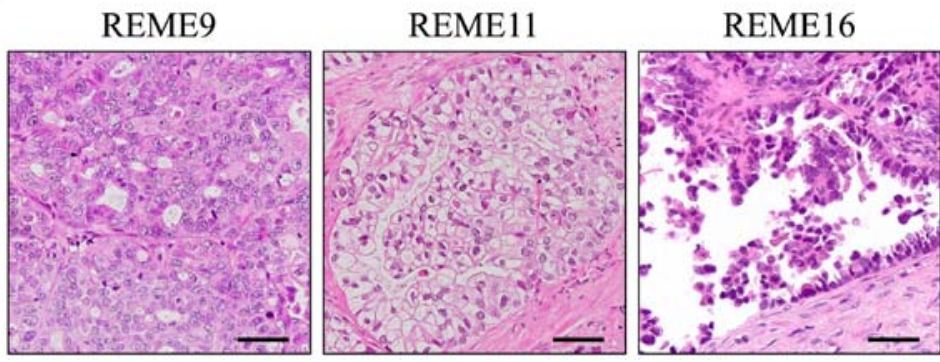

Figure 3. In vivo xenograft growth of F-PDOs. (A) Tumor growth in F-PDO-bearing mice. (B) HE staining of tumor sections. The HE-stained images were captured using a x40 objective. Scale bar, $50 \mu \mathrm{m}$. HE, hematoxylin and eosin; F-PDO, Fukushima patient-derived organoid.
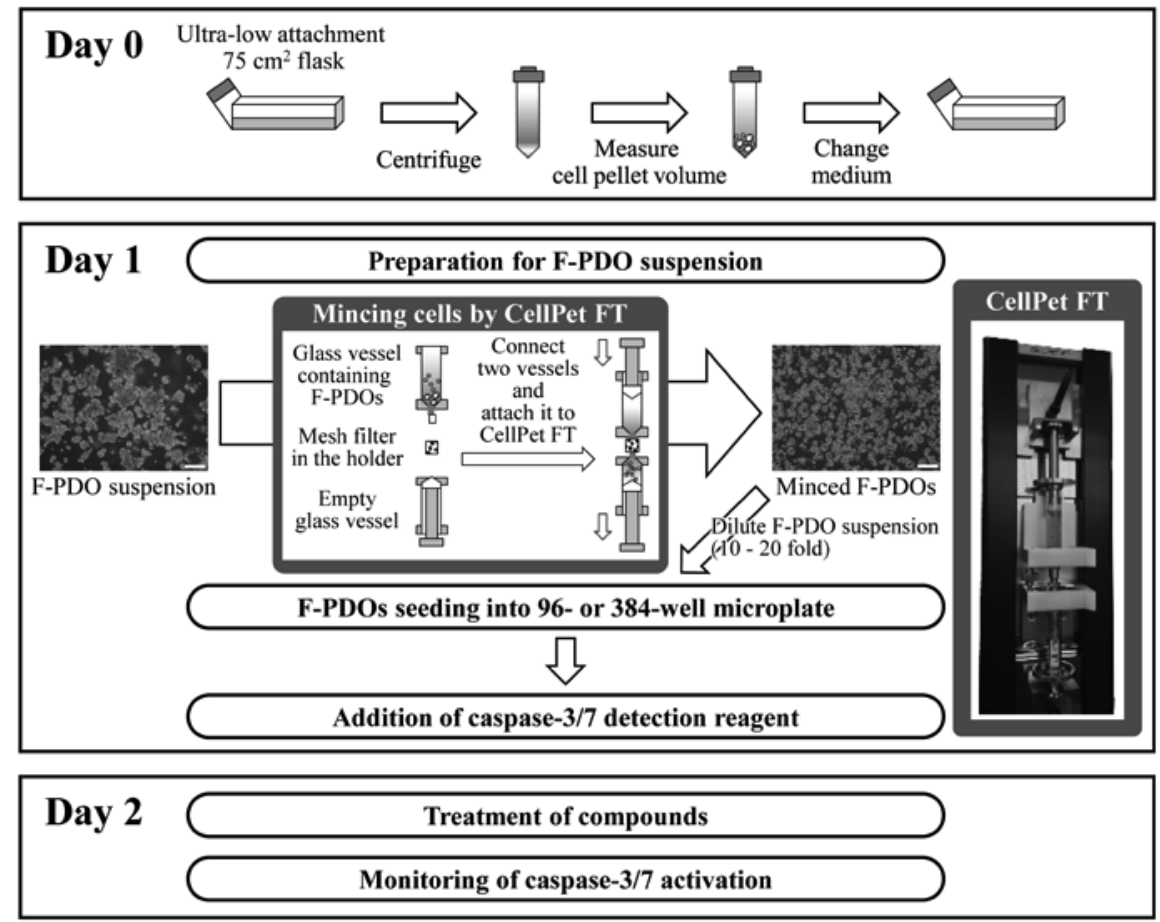

Incubate for 6 days

Day 8 Measuring of viable cells with ATP content

Figure 4. Summary of assay protocol using F-PDOs and 96- or 384-well microplates. Scale bar, $200 \mu \mathrm{m}$. F-PDO, Fukushima patients-derived organoid; ATP, 5 ' adenosine triphosphate.

is suitable for HTS when this value is $>0.5$. The growth rate of F-PDOs in the plates was 2.31-5.16 fold (Table III). The control data points in the 96-well plate assay exhibited little variability, with $\mathrm{CV}$ values of $1.12,3.08$ and $0.74 \%$ and with a calculated Z'-factor of 0.97, 0.91 and 0.98 , for REME9, 11 and 16, respectively (Table III). These results suggested that this assay had excellent performance for HTS. The CV and $\mathrm{Z}^{\prime}$ values for REME9 and 16 in 384-well plates were also 
A

REME9
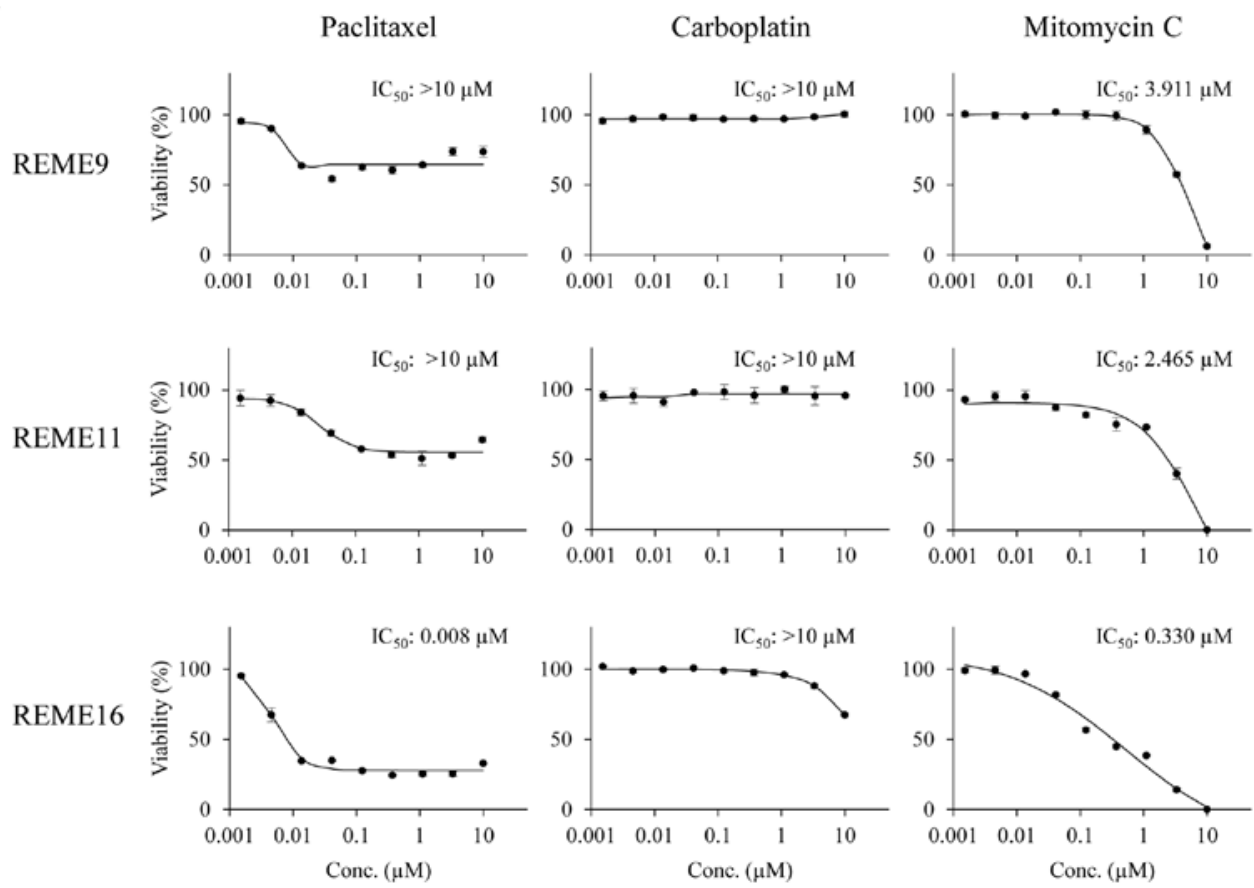

$\mathrm{B}$
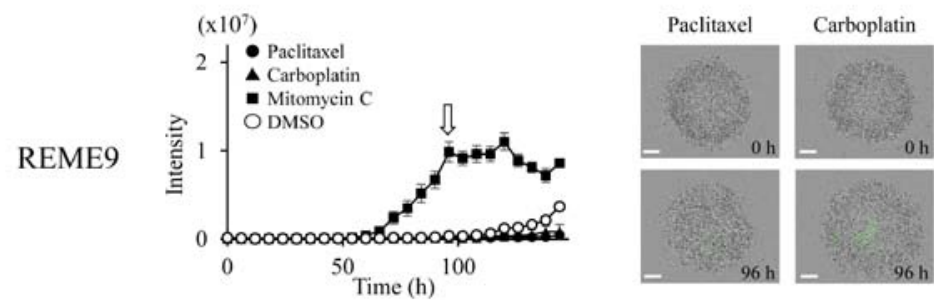

Mitomycin C
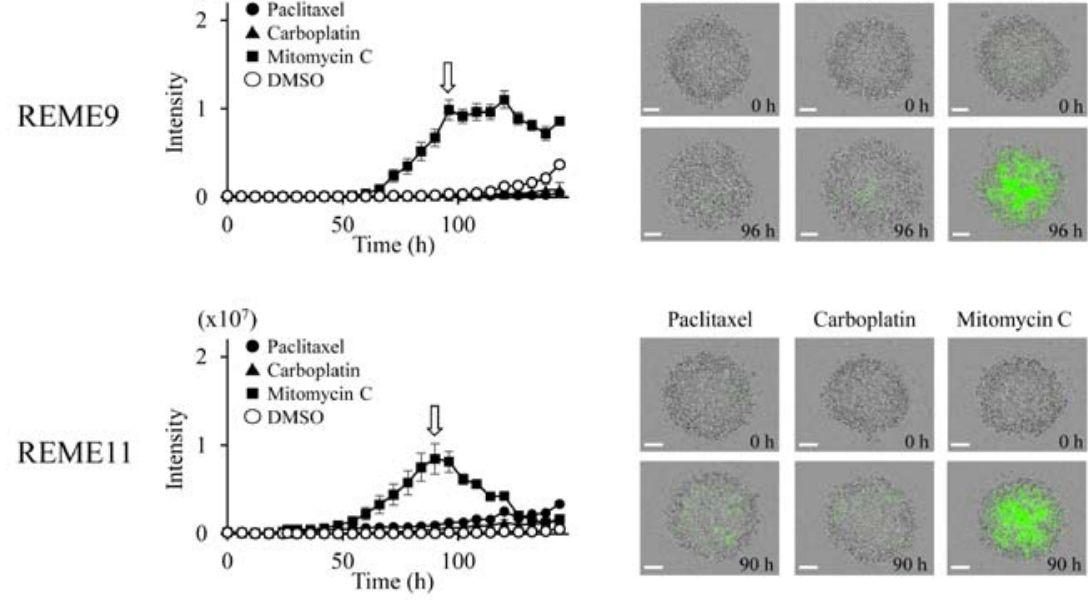

Mitomycin C
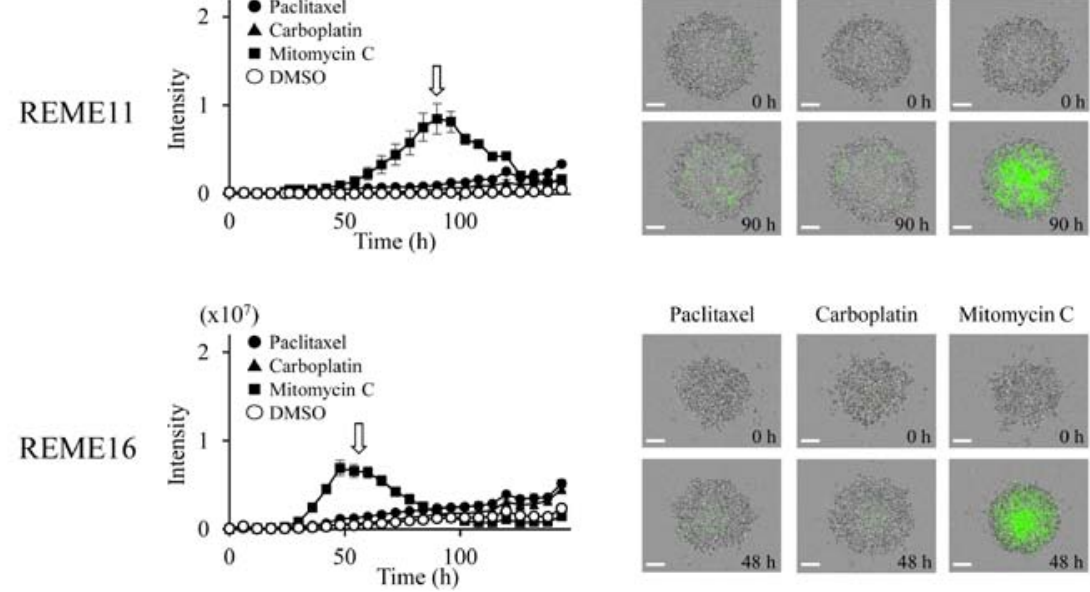

Mitomycin C
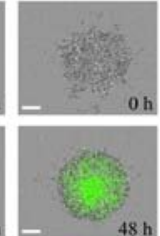

Figure 5. Response of F-PDOs to clinically used chemotherapeutics. (A) Dose-response curve of F-PDOs to anticancer agents. The F-PDOs were minced, seeded in 96-well plates, and treated with nine different concentrations (between $10 \mu \mathrm{M}$ and $1.5 \mathrm{nM}$ ) of paclitaxel, carboplatin or mitomycin C for 6 days. The data represent the mean \pm standard deviation of triplicate experiments. (B) Caspase-3/7 levels in F-PDOs treated with paclitaxel, carboplatin or mitomycin C. The time course quantification of caspase-3/7 fluorescence in F-PDOs treated with $10 \mu \mathrm{M}$ each agent is presented. The graphs represent the time-course of fluorescence intensities, representing caspase-3/7 activity, between 6 and $144 \mathrm{~h}$ post-drug treatment. The data represent the mean \pm standard deviation of triplicate experiments. For each F-PDO, images were captured at $0 \mathrm{~h}$ or the time when the fluorescence intensity reached its maximum following the drug treatment, as indicated by the arrows. Scale bar, $400 \mu \mathrm{m}$. F-PDO, Fukushima patient-derived organoid.

good; specifically, the CV values were 5.38 and $4.44 \%$ and the Z'-factor values were 0.84 and 0.87 , for REME9 and 16 , respectively (Table III). However, REME11 was unsuitable for 384-well plate assays, since the $\mathrm{CV}$ and $\mathrm{Z}$-factor values were $21.65 \%$ and 0.35 , respectively. Consequently, HTS was performed with F-PDOs using 96- or 384-well plates to evaluate anticancer agents.

Evaluation of anticancer agents using F-PDOs. To investigate the sensitivity of F-PDOs to anticancer agents using our HTS 


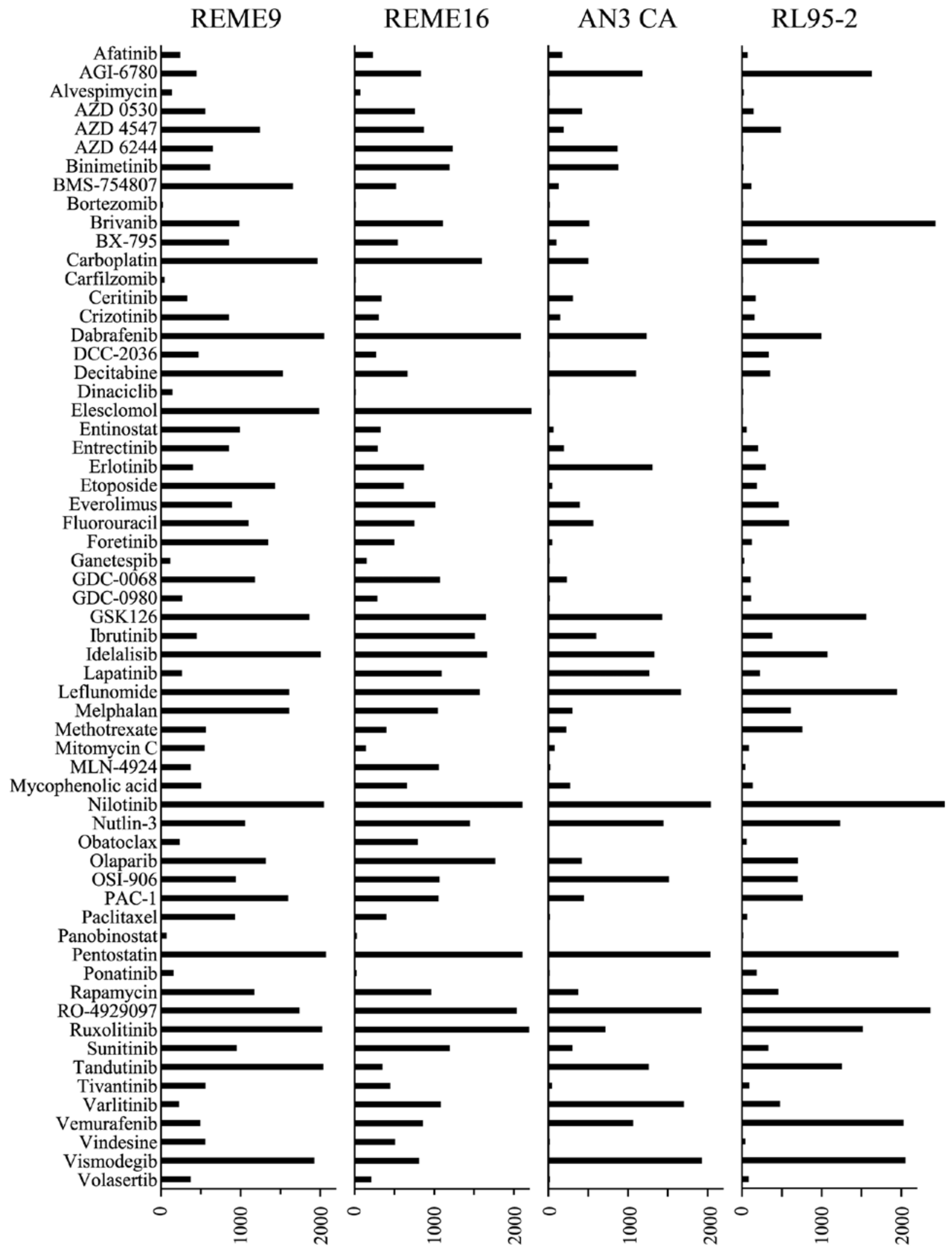

Figure 6. High-throughput assay of anticancer agents using Fukushima patient-derived organoid in 384-well plates. The bar graphs represent the area under the curve values calculated from the growth inhibition assay, using 61 anticancer agents at a range of $0.1-20 \mu \mathrm{M}$. The data represent the mean of triplicate experiments.

system, growth inhibition and apoptosis were assessed using REME9, 11 and 16 lines treated with three representative anticancer agents, specifically paclitaxel, carboplatin and mitomycin C, in 96-well plates. Paclitaxel and carboplatin are used as the standard clinical treatments for endometrial cancer. F-PDOs were treated with the drugs $24 \mathrm{~h}$ post-seeding and 
subsequently incubated for 6 days. In addition to counting the viable cells, apoptosis was monitored and analyzed in parallel over time using IncuCyte and CellEvent ${ }^{\mathrm{TM}}$ Caspase-3/7 Green Detection Reagent (Fig. 4). The data points for viable cells and caspase-3/7 activity exhibited little variation (Fig. 5).

The $\mathrm{IC}_{50}$ values of paclitaxel, carboplatin and mitomycin $\mathrm{C}$ in each F-PDO are presented in Fig. 5A. Dose-response curves demonstrated that REME9 and 11 lines were more resistant to all drugs than REME16. In particular, the $\mathrm{IC}_{50}$ values of paclitaxel and carboplatin, the standard therapeutics for endometrial cancer, were $>10 \mu \mathrm{M}$ for REME9 and 11 , whereas the $\mathrm{IC}_{50}$ value of paclitaxel was $0.008 \mu \mathrm{M}$ for REME16. In addition, $10 \mu \mathrm{M}$ carboplatin marginally affected the viability of REME16 cells. By contrast, mitomycin C inhibited the proliferation of all three F-PDOs in a dose-dependent manner and completely suppressed cell survival at a concentration of $10 \mu \mathrm{M}$ (Fig. 5A). These results indicated that REME9 and 11 lines have high resistance $\left(\mathrm{IC}_{50}>10 \mu \mathrm{M}\right)$ to the standard therapeutics used for endometrial cancer (paclitaxel and carboplatin).

To determine whether F-PDO cell death induced by paclitaxel and mitomycin $\mathrm{C}$ was due to apoptosis, the enzymatic activity of caspase-3/7 was monitored over time. Mitomycin C, which inhibited the proliferation of F-PDOs, markedly activated caspase-3/7, suggesting that this agent induces apoptosis at a concentration of $10 \mu \mathrm{M}$ (Fig. 5B). By contrast, despite the fact that paclitaxel inhibited the growth of REME16 cells, it only marginally activated caspase-3/7, similar to that observed for REME9 and 11 (Fig. 5B). Thus, it is possible that the growth inhibition by paclitaxel is not due to an apoptotic effect.

To compare the sensitivity profiles to anticancer agents between F-PDOs (REME9 and 16) and endometrial cancer cell lines (AN3 and RL95-2), 61 anticancer agents (Table II) that are used clinically or in clinical devolvement were evaluated, using the 384-well HTS assay. The overall sensitivity of REME9 and 16 to anticancer agents was lower compared with that of the cell lines (Fig. 6). The sensitivities of REME9 and 16 were very similar, but the profiles of F-PDOs were not similar to those of the cell lines. For example, paclitaxel weakly inhibited the growth of REME9 and 16 cells (Fig. 5A), although it induced a strong growth inhibitory effect on the cell lines (Fig. 6). Thus, the evaluation of anticancer agents using F-PDOs, which possess the characteristics of tumor tissues, may yield more precise information regarding drug efficacy compared with conventional methods. Furthermore, bortezomib, carfilzomib, dinaciclib and panobinostat exerted marked inhibitory effects (AUC values <50) against REME9 and 16. Thus, these anticancer agents may be candidates for the development of novel therapeutic regimens for endometrial cancer.

\section{Discussion}

We have established F-PDOs from a number of tumor tissues and validated their characteristics relative to those of their source tumor tissue. Furthermore, genome analysis of F-PDOs, using next generation sequencers, is now in progress to understand their genetic characteristics. Gene expression data for the F-PDOs from xenograft mice were additionally obtained. The gene expression profiles of F-PDOs between culture and xenograft samples were virtually identical (data not shown). Thus, the characteristics of F-PDOs in xenograft mice are maintained in culture, and are similar to those of their source tissues. The primary difference between F-PDOs and other tumor organoids is the method of establishment. For this method, source tumors are not disrupted using enzymes, for example trypsin and collagenase; rather, they are minced by physical cutting, unlike previously reported methods (12-23). In addition, these enzymes are not even used during passaging for long-term culturing or assays. Therefore, it was hypothesized that the maintenance of F-PDOs retains the conditions of the heterogeneous source tumors. The characteristics of F-PDOs recapitulate the histological architecture and expression profile of the source tumor tissues, even following long-term expansion or grafting in immunodeficient mice. Thus, the F-PDOs were stably and continuously used to evaluate anticancer agents.

The characteristics of F-PDOs are unsuitable for HTS using a 96-well or 384-well formats to evaluate compounds, as these structures exhibit various and non-uniform sizes, in addition to forming large clusters in culture. To solve this problem, CellPet FT was used, which is able to mince cell spheroids without damaging them using a mesh filter. This results in uniform cell sizes, and when this was applied, the development of a precision HTS platform using F-PDOs was successful. This protocol, using HTS, is appropriate for screening anticancer agents from a large compound library. In addition, it may be possible to assess the efficacy of compounds identified by HTS using mice engrafted with F-PDOs used for the original assay.

The present study evaluated the standard chemotherapeutics (paclitaxel and carboplatin) that are used for endometrial cancer using REME9, which was derived from a patient who did not respond to paclitaxel and carboplatin. Accordingly, the inhibitory effects of paclitaxel and carboplatin against this cell line were weak (Fig. 5A). These results suggested that F-PDOs may reflect the clinical status of source tumors in terms of response to drugs. Thus, this assay system may facilitate the evaluation of anticancer agents under conditions that reflect clinical conditions more accurately compared with conventional methods, and may aid the discovery of markers to predict the pharmacological effects of anticancer agents.

In conclusion, the results of the present study demonstrated that F-PDOs are superior to conventional cell lines for identifying potential novel therapeutic targets, thus presenting opportunities for drug testing and advances in personalized medicine approaches.

\section{Acknowledgements}

Not applicable.

\section{Funding}

The present study was supported by grants for Translational Research Programs from Fukushima Prefecture.

\section{Availability of data and materials}

The datasets used during the present study are available from the corresponding author upon reasonable request. 


\section{Authors' contributions}

MT, SW, KK and KF conceived and designed the experiments. HT, AH, HH, GH, NT, MR, GM, YY, EI, JII, YD, SS and TW performed the experiments. HT, AH, HH, GH, SW and MT analyzed the data and wrote the paper. MT revised the paper.

\section{Ethics approval and consent to participate}

These experiments were performed with the approval of the Institutional Animal Care and Use Committee of Fukushima Medical University (approval nos. 27011, 29035; Fukushima, Japan).

\section{Patient consent for publication}

Not applicable.

\section{Competing interests}

The authors declare that they have no competing interests.

\section{References}

1. Sharma SV, Haber DA and Settleman J: Cell line-based platforms to evaluate the therapeutic efficacy of candidate anticancer agents. Nat Rev Cancer 10: 241-253, 2010.

2. Shamir ER and Ewald AJ: Three-dimensional organotypic culture: Experimental models of mammalian biology and disease. Nat Rev Mol Cell Biol 15: 647-664, 2014.

3. Arrowsmith J and Miller P: Trial watch: Phase II and phase III attrition rates 2011-2012. Nat Rev Drug Discov 12: 569, 2013.

4. Arrowsmith J: Trial watch: Phase II failures: 2008-2010. Nat Rev Drug Discov 10: 328-329, 2011.

5. DiMasi JA, Reichert JM, Feldman L and Malins A: Clinical approval success rates for investigational cancer drugs. Clin Pharmacol Ther 94: 329-335, 2013.

6. Tentler JJ, Tan AC, Weekes CD, Jimeno A, Leong S, Pitts TM, Arcaroli JJ, Messersmith WA and Eckhardt SG: Patient-derived tumour xenografts as models for oncology drug development Nat Rev Clin Oncol 9: 338-350, 2012.

7. Siolas D and Hannon GJ: Patient-derived tumor xenografts: Transforming clinical samples into mouse models. Cancer Res 73: 5315-5319, 2013

8. Rosfjord E, Lucas J, Li G and Gerber HP: Advances in patientderived tumor xenografts: From target identification to predicting clinical response rates in oncology. Biochem Pharmacol 91: $135-143,2014$

9. Hidalgo M, Amant F, Biankin AV, Budinská E, Byrne AT, Caldas C, Clarke RB, de Jong S, Jonkers J, Mælandsmo GM, et al: Patient-derived xenograft models: An emerging platform for translational cancer research. Cancer Discov 4: 998-1013, 2014.

10. Gao H, Korn JM, Ferretti S, Monahan JE, Wang Y, Singh M, Zhang C, Schnell C, Yang G, Zhang Y, et al: High-throughput screening using patient-derived tumor xenografts to predict clinical trial drug response. Nat Med 21: 1318-1325, 2015.

11. Weeber F, Ooft SN, Dijkstra KK and Voest EE: Tumor organoids as a pre-clinical cancer model for drug discovery. Cell Chem Biol 24: 1092-1100, 2017.

12. Crespo M, Vilar E, Tsai SY, Chang K, Amin S, Srinivasan T, Zhang T, Pipalia NH, Chen HJ, Witherspoon M, et al: Colonic organoids derived from human induced pluripotent stem cells for modeling colorectal cancer and drug testing. Nat Med 23: 878-884, 2017.

13. Sato T, Stange DE, Ferrante M, Vries RG, Van Es JH, Van den Brink S, Van Houdt WJ, Pronk A, Van Gorp J, Siersema PD, et al: Long-term expansion of epithelial organoids from human colon, adenoma, adenocarcinoma, and Barrett's epithelium. Gastroenterology 141: 1762-1772, 2011.
14. van de Wetering M, Francies HE, Francis JM, Bounova G, Iorio F, Pronk A, van Houdt W, van Gorp J, Taylor-Weiner A, Kester L, et al: Prospective derivation of a living organoid biobank of colorectal cancer patients. Cell 161: 933-945, 2015.

15. Boj SF, Hwang CI, Baker LA, Chio II, Engle DD, Corbo V, Jager M, Ponz-Sarvise M, Tiriac H, Spector MS, et al: Organoid models of human and mouse ductal pancreatic cancer. Cell 160: 324-338, 2015.

16. Gao D, Vela I, Sboner A, Iaquinta PJ, Karthaus WR, Gopalan A, Dowling C, Wanjala JN, Undvall EA, Arora VK, et al: Organoid cultures derived from patients with advanced prostate cancer. Cell 159: 176-187, 2014.

17. Girda E, Huang EC, Leiserowitz GS and Smith LH: The use of endometrial cancer patient-derived organoid culture for drug sensitivity testing is feasible. Int J Gynecol Cancer 27: 1701-1707, 2017.

18. Broutier L, Mastrogiovanni G, Verstegen MM, Francies HE, Gavarró LM, Bradshaw CR, Allen GE, Arnes-Benito R, Sidorova O, Gaspersz MP, et al: Human primary liver cancerderived organoid cultures for disease modeling and drug screening. Nat Med 23: 1424-1435, 2017.

19. Pauli C, Hopkins BD, Prandi D, Shaw R, Fedrizzi T, Sboner A, Sailer V, Augello M, Puca L, Rosati R, et al: Personalized in vitro and in vivo cancer models to guide precision medicine. Cancer Discov 7: 462-477, 2017

20. Kondo J, Endo H, Okuyama H, Ishikawa O, Iishi H, Tsujii M, Ohue $\mathrm{M}$ and Inoue $\mathrm{M}$ : Retaining cell-cell contact enables preparation and culture of spheroids composed of pure primary cancer cells from colorectal cancer. Proc Natl Acad Sci USA 108: 6235-6240, 2011.

21. Endo H, Okami J, Okuyama H, Kumagai T, Uchida J, Kondo J, Takehara T, Nishizawa Y, Imamura F, Higashiyama M, et al: Spheroid culture of primary lung cancer cells with neuregulin 1/ HER3 pathway activation. J Thorac Oncol 8: 131-139, 2013.

22. Kiyohara Y, Yoshino K, Kubota S, Okuyama H, Endo H, Ueda Y, Kimura T, Kimura T, Kamiura $S$ and Inoue M: Drug screening and grouping by sensitivity with a panel of primary cultured cancer spheroids derived from endometrial cancer. Cancer Sci 107: 452-460, 2016.

23. Yoshida T, Okuyama H, Endo H and Inoue M: Spheroid cultures of primary urothelial cancer cells: Cancer tissue-originated spheroid (CTOS) method. Methods Mol Biol 1655: 145-153, 2018.

24. Miura A, Honma R, Togashi T, Yanagisawa Y, Ito E, Imai J, Isogai T, Goshima N, Watanabe $\mathrm{S}$ and Nomura N: Differential responses of normal human coronary artery endothelial cells against multiple cytokines comparatively assessed by gene expression profiles. FEBS Lett 580: 6871-6879, 2006.

25. Okabe N, Ezaki J, Yamaura T, Muto S, Osugi J, Tamura H, Imai J, Ito E, Yanagisawa Y, Honma R, et al: FAM83B is a novel biomarker for diagnosis and prognosis of lung squamous cell carcinoma. Int J Oncol 46: 999-1006, 2015.

26. Higa A, Hoshi H, Yanagisawa Y, Ito E, Morisawa G, Imai JI, Watanabe S and Takagi M: Evaluation system for arrhythmogenic potential of drugs using human-induced pluripotent stem cell-derived cardiomyocytes and gene expression analysis. J Toxicol Sci 42: 755-761, 2017.

27. Ito M, Hiramatsu H, Kobayashi K, Suzue K, Kawahata M, Hioki K, Ueyama Y, Koyanagi Y, Sugamura K, Tsuji K, et al: NOD/SCID/gamma(c)(null) mouse: An excellent recipient mouse model for engraftment of human cells. Blood 100: 3175-3182, 2002.

28. Chijiwa T, Kawai K, Noguchi A, Sato H, Hayashi A, Cho H, Shiozawa M, Kishida T, Morinaga S, Yokose T, et al: Establishment of patient-derived cancer xenografts in immunodeficient NOG mice. Int J Oncol 47: 61-70, 2015

29. Pearson AT, Finkel KA, Warner KA, Nör F, Tice D, Martins MD, Jackson TL and Nör JE: Patient-derived xenograft (PDX) tumors increase growth rate with time. Oncotarget 7: 7993-8005, 2016.

30. Zhang JH, Chung TD and Oldenburg KR: A simple statistical parameter for use in evaluation and validation of high throughput screening assays. J Biomol Screen 4: 67-73, 1999.

This work is licensed under a Creative Commons Attribution-NonCommercial-NoDerivatives 4.0 International (CC BY-NC-ND 4.0) License. 